\title{
Pattern Of Short-Term Volatility Accentuation Within The Trading Day: An Investigation Of The U.S. And European Equity Markets
}

\author{
Deniz Ozenbas, (E-mail: OzenbasD@mail.montclair.edu), Montclair State University
}

\begin{abstract}
Trading friction leads into accentuated stock price volatility over the short term. As such, shortterm accentuated volatility can be viewed as symptomatic of a market with increased inefficiencies in the price discovery process. If price discovery is marked by price swings, runs and reversals, then short period (intra-day) volatility is heightened in that market. In this study, we use return series with various differencing intervals that are as short as half-hour and as long as two weeks to investigate the short-term volatility accentuation in five different equity markets: the Nasdaq Stock Market and the New York Stock Exchange in the US, and the London Stock Exchange, Deutsche Boerse and Euronext Paris in Europe. In all these markets, we investigate the individual stocks that make up a major index during the calendar year 2000. Variance-ratio statistics are employed to investigate the quality of these five markets. Results confirm an intraday reverse J-shaped pattern of half-hour volatility in these markets. The evidence also suggests an accentuation of volatility during longer periods, such as 24-hour intervals. This accentuation appears to subside when we extend our differencing interval to longer periods such as one-week or two-week returns.
\end{abstract}

\section{PART 1: INTRODUCTION}

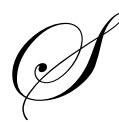

ecurities and Exchange Commission encourages market centers to provide detailed disclosure of their execution quality (also known as market quality). However, there is no single metric to measure market quality. Even the Commission writes in its Report on the Comparison of Order Executions Across Equity Market Structures (2001) that "There is no single, all-encompassing measure of market quality. For example, although effective spread is an important component, some investors may prefer a fast execution at a guaranteed price to a slower execution with the possibility of price improvement. In addition, effective spread measures the handling of a single trade, without considering the ability of a market structure to absorb a series of trades with minimal price volatility. "In this study we concentrate on "the ability of a market structure to absorb a series of trades with minimal price volatility" and investigate intra-day price volatility accentuation as a single (inverse) measure of market quality. We propose it as one of the metrics to compare order executions across different equity market structures.

Since a major function of a marketplace is to establish the prices of the assets traded in it, then the quality of the market can be measured by how efficient it is in performing this task. The complexity of finding the price that best reflects the broad market is particularly magnified at times of stress. Examples include periods around critical news releases, major market moves, and following a period of non-trading such as the overnight close. A central premise of this study is that the quality of a market can best be evaluated during the stressful periods. Market openings are an excellent candidate to focus on - they are stressful, and they occur daily.

In this study, we investigate the level of short-term volatility accentuation (with particular emphasis on market openings) and contrast it to longer-term volatility in five different equity markets: The New York Stock 
Exchange and NASDAQ in the US, and The London Stock Exchange, Deutsche Boerse, and Euronext Paris in Europe. As a result, we investigate short-term price volatility accentuation both inter-temporally and across several stock markets, and assess it as an inverse measure of equity market quality. We particularly pay attention to how short-term (half-hour) volatility changes throughout the trading day.

The ability of an equity market to accommodate a series of trades and incorporate new information into stock prices with minimal price volatility is an important aspect of its quality. If the price discovery process is marked by price swings, runs and reversals, in other words if the price discovery process is not efficient, then short-term volatility will be heightened in the market. Heightened short-term volatility makes trading more difficult and hence may scare liquidity away. Furthermore, increased short-term volatility can invite more speculative short-term trading into the market (day trading). Even though some traders might be able to profit from it, high short-term volatility is costly to the market in aggregate. It discourages trades, lowers portfolio performance for most traders and makes portfolio returns more uncertain for everybody. Consequently, accentuated volatility is an indicator of price discovery inefficiencies in the market.

After establishing that accentuated volatility is a meaningful (inverse) measure of market quality, we assess how the Nasdaq, New York Stock Exchange, Euronext Paris ${ }^{1}$, Deutsche Boerse and the London Stock Exchange stocks fare according to this measure. By investigating this issue across different market centers with different market structures, we establish the universality of the positive link between volatility and trading costs. We are also able to draw conclusions on whether or not there is any significant variation across different market structures on this issue.

The study enhances and extends the existing literature in several ways: It investigates short-term stock price volatility as a way of capturing the trading friction during the trading day. To that extent, it is an attempt to expand the studies on trading friction that use daily data (e.g. Stoll (2000)). We are also contrasting short-term volatility with long-term volatility (such as from daily and weekly return series) to measure the extent of volatility accentuation during shorter periods. An important contribution is the comparison of volatility accentuation at different times of the trading day. Even though, several studies find a U-shaped intra-day volatility pattern, the level of concavity of the Ushape across different market centers has not been analyzed before. We use data from five different equity markets, in the US and in Europe, with a wide spectrum of different market structures and opening procedures employed. As a result, we are able to investigate whether or not patterns of volatility differ across various market centers and market opening procedures. Instead of using data on stock indices, we use tick-by-tick data on individual stocks in each market. Since price discovery and trading friction occur on an individual stock basis, we use individual stock price data in all markets in order to capture trading friction more accurately.

\section{PART 2: LITERATURE REVIEW}

Trading friction in financial markets measures the difficulty with which an asset is traded. Stoll (2000) uses daily data to investigate trading friction for the NYSE stocks, and finds that trading frictions are particularly pronounced at the opening of a market and can be captured by measuring the opening volatility. However, Stoll's definition of opening volatility takes into consideration only the first price of the day, and not the price changes immediately following the opening. Stoll's definition of opening volatility is in the spirit of Amihud and Mendelson (1987) and Stoll and Whaley (1990). Before Amihud and Mendelson (1987), daily volatility was traditionally calculated from close to close returns. Theirs was the first academic study that compared the variance of the open-toopen returns to the close-to-close returns of the stocks of the DJ Industrial Index. They found that open-to-open returns had a higher variance compared to the close-to-close returns

The importance of the differencing interval when measuring variance has been established in the literature. Hasbrouck and Schwartz (1988), and Campbell, Lo and MacKinlay (1997) are two studies that show that the variance

\footnotetext{
${ }^{1}$ Euronext is a market born from the merger of the exchanges of Amsterdam, Brussels and Paris. In this study, data from only Euronext Paris is used.
} 
estimated for the same data sample, however at different sampling frequencies, give different results. ${ }^{2}$ This is in contrast to a random walk model of stock returns that would give the same number for variance no matter how the sampling frequency is set as long as the same calendar period is investigated. Furthermore, if stock prices follow a random walk then we expect to find evidence of neither positive nor negative autocorrelation.

Intra-day patterns in volatility were first documented by Wood, McInish and Ord (1985), Jain and Joh (1988) and Harris (1986). Subsequently, this area has been investigated by other academic studies including Madhavan, Richardson and Roomans (1997), and Gerety and Mulheren (1994). Generally, these studies find a U-shape in volume and volatility across the markets studied. One of the more important differences between these studies and the current one is that, in these studies, patterns of stock indices are investigated as opposed to the patterns of individual stocks that are investigated in the current study. Price discovery takes place on an individual stock basis, and one of the primary reasons for the accentuated intra-day volatility is the errors in price discovery for the individual stocks that occur during the trading day. By investigating individual stocks, we would like to capture the extent of this phenomenon. Furthermore, another important difference between our study and some of the studies mentioned above is that these studies calculate and contrast the volatility of 24-hour returns, albeit beginning the 24 hour period at different times of the day. In other words, they measure 9:30 to 9:30 volatility, 10:00 to 10:00 volatility etc. Also, in addition to measuring open to open and close to close (ie. 24 hour) and weekly and bi-weekly volatilities, in this study we concentrate on shorter term volatility by investigating the pattern of intra-day half hour and open to close volatilities.

Admati and Pfleiderer (1988) provide a theoretical explanation for the intra-day U-shaped patterns in volume and volatility in which concentrated-trading patterns arise endogenously as a result of the strategic behavior of liquidity traders and informed traders. Several other researchers argue that the trading costs should increase towards the end of the trading day, creating more volume and volatility near the closing of trading. Examples include Bessembinder (1994), and Brock and Kleidon (1992).

\section{PART 3: A DISCUSSION OF VARIANCE RATIOS}

In this study, we use variance ratios to measure the extent of accentuated short-term volatility. An important implication of random walk hypothesis is that variance of the random walk increments (measured by the natural logarithm of price relatives) is a linear function of the time period. In other words, if returns of stock prices follow a random walk, it should not matter whether we use hourly, daily or weekly time increments to measure the return variance. They should all give approximately the same variance once they are adjusted for the differencing interval. Under the random walk hypothesis, $\operatorname{Var}\left(r_{t}(2)\right)$ should be twice $\operatorname{Var}\left(r_{t}(1)\right)$ and the following variance ratio $\operatorname{VR}(2)$ $=\frac{2 \operatorname{Var}\left[\mathrm{r}_{\mathrm{t}}(1)\right]}{\operatorname{Var}\left[\mathrm{r}_{\mathrm{t}}(2)\right]}$ should be one. However, existence of serial autocorrelation in stock returns causes the variance ratios to differ from one. Again we can demonstrate this for the two-period variance ratio as follows:

$$
\begin{aligned}
& \operatorname{VR}(2)=\frac{2 \operatorname{Var}\left[\mathrm{r}_{\mathrm{t}}(1)\right]}{\operatorname{Var}\left[\mathrm{r}_{\mathrm{t}}(2)\right]}=\frac{2 \operatorname{Var}\left[\mathrm{r}_{\mathrm{t}}\right]}{\operatorname{Var}\left[\mathrm{r}_{\mathrm{t}}+\mathrm{r}_{\mathrm{t}-1}\right]} \\
& \operatorname{Var}\left[r_{t}+r_{t-1}\right]=\operatorname{Var}\left[r_{t}\right]+\operatorname{Var}\left[r_{t-1}\right]+2 \operatorname{Cov}\left[r_{t}, r_{t-1}\right]=2 \operatorname{Var}\left[r_{t}\right]+2 \operatorname{Cov}\left[r_{t}, r_{t-1}\right] \\
& \operatorname{VR}(2)=\frac{2 \operatorname{Var}\left[\mathrm{r}_{\mathrm{t}}\right]}{2 \operatorname{Var}\left[\mathrm{r}_{\mathrm{t}}\right]+2 \operatorname{Cov}\left[\mathrm{r}_{\mathrm{t}}, \mathrm{r}_{\mathrm{t}-1}\right]} \\
& \operatorname{VR}(2)=[1+\rho(1)]^{-1}
\end{aligned}
$$

\footnotetext{
2 Their methodology is further discussed in part 3.
} 
where $\rho(1)$ is the first order autocorrelation of the return series. Since the denominator of the above variance ratio is the variance of two-period returns series, we are only concerned with the first order autocorrelation. However, when the long-period return series are more than double the short-period return series, then we need to investigate higher order autocorrelation terms than the first order. ${ }^{3}$ The VR(2) formula derived above shows that while a positive autocorrelation causes the $\operatorname{VR}(2)$ to be less than one, negative serial autocorrelation will cause the $\operatorname{VR}(2)$ to be greater than one. In other words, under positive autocorrelation, variance of longer periods will be larger than sum of the variances of shorter periods. Under negative autocorrelation, variance of longer periods will be smaller than sum of the variances of shorter periods.

\section{PART 4: DATA}

Two domestic markets are studied: The New York Stock Exchange and the Nasdaq Stock Market. Intraday trades and quotes data for both markets were obtained from the TAQ (Trades and Quotes) database. The study period is the calendar year 2000. We include in our study the stocks that make up a major index for both market centers. For Nasdaq, we choose the stocks that were a part of the Nasdaq 100 index on December 31, 2000 and for NYSE, we choose the stocks that were a part of the S\&P 100 index on December 31, 2000. Of course, the S\&P 100 index contains a few Nasdaq stocks and we eliminate these stocks from our NYSE sample. We divide the calendar year into two six-month periods and run our tests separately for these two periods in order to check for robustness. In addition, we perform extensive error-filtering of the data.

The three foreign markets that are studied include the Euronext Paris (Paris Bourse), Deutsche Boerse and the London Stock Exchange. For each market we study the transaction records, during the year 2000, of stocks that make up a major index. We use the BDM database of the Paris Bourse for the transactions of the stocks that make up the CAC 40 index, and the Transaction Data Service database of the London Stock Exchange for the transactions of the stocks that make up the FTSE 100 index. The transactions database of the stocks that make up the DAX 30 index was obtained from the Deutsche Boerse. Trading hours at the Paris Bourse at the beginning of 2000 were 9:00 am to 5:00 pm. The hours were extended on April $1^{\text {st }}$ to 9:00 am to 5:30 pm. The market opens with a call auction within the first minutes after 9:00 am, and there is another call auction that takes place about 5 minutes after the close. We divide the study period into two intervals: the first interval is from January $1^{\text {st }}$ to March $31^{\text {st }}$ and the second period is from April $2^{\text {nd }}$ to December $31^{\text {st }}$. The first interval corresponds to the shorter trading hours and the second interval corresponds to the longer trading hours. Trading hours for Deutsche Boerse at the beginning of the year were 9:00 am to $5: 30 \mathrm{pm}$, but they were extended to 9:00 am to 8:00 pm on June $2^{\text {nd }}, 2000$. Similar to the Paris Bourse, trading opens with an opening call auction that takes place within the first few minutes after 9:00 am. There is an intraday call auction a few minutes after 1:00 pm. Also, again similar to the Paris Bourse, there is a call auction that takes place about 5-10 minutes after the close. Before the extension of trading hours, the closing call was around 5:40 pm. After the extended trading hours, this call is kept as the second intraday call auction and the closing call auction takes place few minutes after 8:00 pm. Again, we divide the study period into two intervals. The first interval is from January $1^{\text {st }}$ to May $31^{\text {st }}$, corresponding to the shorter trading hours, and the second interval is from June $3^{\text {rd }}$ to December $31^{\text {st }}$, corresponding to the longer trading hours. Trading hours for the London Stock Exchange are 8:00 am to 4:30 pm. A closing call auction was introduced on May $30^{\text {th }} 2000$ to the London Stock Exchange. Starting with this date, trading has been ending with a call auction that takes place several minutes after 4:30 pm. We again divide the study period

${ }^{3}$ Hasbrouck and Schwartz (1988) and Campbell, Lo and MacKinlay (1997) show that an m-period variance ratio will be a function of the m-1 autocorrelation coefficients as follows:

$$
\mathrm{VR}(\mathrm{m}) \equiv \frac{m \operatorname{Var}\left[r_{t}(1)\right]}{\operatorname{Var}\left(r_{t}(m)\right)}=\left[1+2 \sum_{k=1}^{m-1}\left(\frac{m-k}{m}\right) \rho(k)\right]^{-1}
$$

This equation shows that the m-period variance ratio is a function of the first m-1 autocorrelation coefficients, with linearly declining weights. If higher-order intertemporal correlations are predominantly positive (negative), then long term return variance will be greater (smaller) than the sum of short term return variances. If higher order autocorrelation coefficients are pre-dominantly negative then we should observe accentuated short-term volatility in the equity prices. 
into two intervals. The first interval is from January $1^{\text {st }}$ to May $29^{\text {th }}$, corresponding to the period without the closing call auction, and the second interval is from June $1^{\text {st }}$ to December $31^{\text {st }}$, corresponding to the period with the closing call auction.

In this paper, in tables 2 through 6 , we only present the intra-day results for the second half of 2000, as described above, for all market centers in order to save space. The findings are consistent between the first and second study periods, and the first study period results are available upon request.

\section{PART 5: EMPIRICAL METHODOLOGY AND RESULTS}

We define the following differencing intervals: Intra-day (half-hour) variances, open-to-close variances, open-to-open variances, close-to-close variances, one-week variances and two-week variances. We then calculate the ratios of shorter period variances to longer period variances in order to measure the extent of variance accentuation or diminution at shorter differencing intervals.

We capture the intra-day patterns of volatility by dividing the trading day into several half-hour periods. For example, in a market with a trading day that is six and a half hours long (eg. New York Stock Exchange and Nasdaq) we have thirteen half-hour periods: such as 9:30 to10:00, 10:00 to 10:30 ... 3:30 to 4:00.

The reason for dividing the trading day into several sub-periods is twofold. First, focusing on a certain halfhour interval across days helps to break the effect of the factors that create the inter-temporal autocorrelation. Since factors such as momentum trading and market impact build over time, investigating consecutive periods would have led us into underestimating their effect on trading costs. Second, we are able to investigate how the trading friction changes across the trading day, and whether certain periods of the day could be characterized by having higher levels of execution costs. We calculate the volatility of stock returns for each of the half-hour intervals separately in an attempt to capture the relative volatility of different periods of the trading day, such as the opening half-hour or the closing half-hour.

In all the markets, findings confirm a U-shaped intra-day volatility pattern, with a more pronounced spike at the beginning of the trading day. These findings confirm that the period following the opening and just before the end of trading are periods of particular stress, and require particular attention. Intra-day volatility patterns show that volatility is accentuated in all markets studied during the beginning of trading in the morning and towards the close of trading. This result clearly suggests that these are periods characterized by less efficient price discovery (high trading friction). However, the underlying reasons for the greater uncertainty (and the more difficult price discovery) are different for the opening and closing periods. Price discovery in the morning is more difficult compared to the rest of the trading day mainly because there is information cumulated during the non-trading hours that needs to be translated into prices during this period. Furthermore, following a period of non-trading there could be greater heterogeneity in interpretation of the new information and, thus, more variation in opinions about the direction of stock prices. On the other hand, towards the end of the day trading becomes more stressful due to the impending close of trading. Namely, as the market close approaches traders feel a need to close their positions and/or rebalance their portfolios before the non-trading period ends in order to minimize the risk of carrying their positions overnight. This increased trading pressure translates into increased volume and accentuated volatility in stock prices.

We also calculate the variance of each stock in our sample for longer differencing intervals than the intra-day periods. The following variances (for all stocks across the five markets and two study periods) are calculated: open-toclose variance, open-to-open variance, close-to-close variance, one-week variance and two-week variance. To calculate the variance ratios, we scale each variance mentioned above to a 24 -hour variance. For example, the variance of one-week returns, that covers 5 trading days, is divided by 5 to make it comparable to the variance of close-to-close returns. The scaled variances are as follows, 


$$
\begin{array}{ll}
\text { INT: } & \sigma_{j, i}^{2} *(\mathrm{n}+1) \\
\text { OC: } & \sigma_{o c, i}^{2} *(\mathrm{n}+1 / \mathrm{n}) \\
\text { OO: } & \sigma_{o o, i}^{2} \\
\text { CC: } & \sigma_{c c, i}^{2} \\
\text { OW: } & \sigma_{o w, i}^{2} *(1 / 5) \\
\text { TW: } & \sigma_{t w, i}^{2} *(1 / 10)
\end{array}
$$

where $\mathrm{n}$ is the number of half hour periods per one trading day, $\mathrm{j}$ is the subscript for the intra-day half-hour period, and $i$ is the subscript for the particular stock.

In Table 1, we report the following longer period variance ratios for all the markets: OC / TW, OO / TW, CC / TW, OW / TW. In all of these variance ratios, the denominator (the longer differencing interval) is the scaled twoweek variance. Since we expect that trading friction would get washed out over the longer term, two-week variance should be capturing the true volatility (that stems from permanent, information related price shifts) of the securities investigated instead of accentuated volatility due to trading friction. As a result, through using this set of variance ratios, we are able to investigate whether or not open-to-close, open-to-open, close-to-close, and one-week variances are accentuated.

Findings show that one-week variance is statistically indistinguishable from two-week variance for all markets. This finding confirms that trading friction is washed out when variance is calculated in sufficiently long differencing intervals. Clearly, a one-week differencing interval is long enough for the volatility accentuation due to friction to dampen appreciably. On the other hand, open-to-open variance is significantly accentuated in the London Stock Exchange and Euronext Paris for both of the study periods, and in Nasdaq and Deutsche Boerse for at least one of the study periods. The results for the close-to-close variance are less consistent than open-to-open variance results. We find that close-to-close variance is accentuated in comparison with the two-week variance in the London Stock Exchange, Euronext Paris and the Deutsche Boerse for only one study period in each market. This result is consistent with the academic literature that find opening variances to be higher than closing variances.

Open-to-close variance, on the other hand, is not statistically greater than two-week variance for all the markets except for the London Stock Exchange. Since the open-to-close period does not include the overnight period, this result implies that there is significant price volatility overnight (that might be due to information arrival overnight). The second period (July-December 2000) for the NYSE is an outlier in the sense that the variance ratios are pre-dominantly less than 1 , albeit not statistically significantly except for the OC/TW, during this period. This was a period of important change in the NYSE since decimalization has been introduced during this period. Certainly, this might be the factor explaining the findings. However, the impact of decimalization needs to be investigated more formally before reaching any firm conclusions. Also in Table 1, the percentages of stocks (for each market and study period) that have variance ratios more than unity are also reported. As expected, these percentages are consistent with the variance ratios we calculated, and show that, for most of the markets, shorter period volatilities are accentuated.

In Tables 2 through 6, each intra-day half-hour period volatility accentuation is reported as compared to open to close, close to close, open to open, one week and two week volatilities. ${ }^{4}$ Results show that the accentuated intraday volatility widely reported by academic studies and mainstream media is a phenomenon that belongs to the opening (and in some market centers to the closing) of the trading only, and not to other intra-day periods during the middle of the trading day. As discussed in the previous paragraphs long-term volatility as measured by using daily or weekly price changes captures permanent and information-driven shifts in prices as opposed to intra-day price

\footnotetext{
${ }^{4}$ As mentioned in Part 3, we report the findings only for the second half of 2000 for all market centers in order to save space. The findings are consistent between the first and second study periods, and are available upon request.

Also, the percentages of stocks that have variance ratios more than unity are reported in these tables.
} 
changes that are largely attributable to trading friction. As a result, through calculating the relative accentuation of intra-day periods compared to longer differencing intervals, we can infer the efficiency of price discovery in these markets during the more stressful periods such as the opening or closing of trading.

In all markets we study, market opening is a period of particular stress and the volatility accentuation is observed for about two half-hour periods into the start of trading. One notable exception is the London Stock Exchange. In this market, we observe an even higher volatility accentuation that lasts about four half-hour periods into the start of trading. We are unable to explain this result fully, but note that trading volume at the open is low for London. ${ }^{5}$ The lower volume indicates that institutional investors in London tend to avoid trading at the open. ${ }^{6}$ While institutional traders in the US may also tend to avoid the open, retail trading interest in the US (and continental Europe) provides ample volume at the open and, in so doing, may lead to better price discovery.

We also find some evidence of accentuated short term volatility just before market closes, however not at as great en extent as we found for the opening period. More specifically, volatility is accentuated compared to longer differencing intervals during the market closings for NASDAQ, Euronext Paris and London Stock Exchange, with once again the most pronounced accentuation being observed at LSE. It was discussed in part 3 that Deutsche Bourse extended its trading hours from 9:30 am - 5:30 pm to 9:30 am - 8:00 pm. However, these extended hours were largely unsuccessful during our sample period with very little trading volume observed after 5:30 $\mathrm{pm}^{7}$. Table 6 shows that despite the extended trading hours, $5: 30 \mathrm{pm}$ is still the effective close with minimum price movement from 5:30 pm to 8:00 pm. On the other hand, the call auction that follows the 8:00 pm close seems to be a meaningful price discovery vehicle.

\section{PART 6: DISCUSSION}

An essential function of a marketplace is to bring buyers and sellers together to discover the prices of securities traded in it. However, the process of price discovery in any equity market is not without trading friction. Trading friction can be defined as all of the factors that collectively create pricing errors (that lead to less than efficient price discovery). Examples of factors that create pricing errors include the bid-ask spread that causes prices to alternate between the bid price and the ask price, the price impact of large trades that push the prices up for a buyerinitiated transaction or down for a seller-initiated transaction, herding behavior (momentum trading) that leads to price runs up or down, and under or overreaction to news announcements. There are two important commonalities between the factors that create the trading friction. First, they create turbulence around the prevailing level of the security price. Second, their impact is only temporary in nature. That is, prices get corrected and revert back to their previous levels over the longer period.

Consequently, trading friction is expected to lead into accentuated volatility only over the short term. In other words, short-term accentuated volatility can be viewed as symptomatic of a market with increased inefficiencies in the price discovery process. Despite the fact that some temporary pricing errors may be unavoidable in an equity market, it is certainly desirable to minimize the level of trading friction that is the outcome of avoidable inefficiencies in the price discovery process. A market with less trading friction is certainly more efficient in discovering prices and will be a preferable trading venue for most market participants. It is from this perspective that we view short-term accentuated volatility as an inverse measure of market quality.

In this study, we investigate the level of short-term volatility accentuation and contrast it to longer-term volatility in five different equity markets: The New York Stock Exchange and NASDAQ in the US, and The London Stock Exchange, Deutsche Boerse, and Euronext Paris in Europe. For each market, we repeat our investigation for two separate study periods to check for the consistency of our results. Also, in all the markets in this study, we choose the most liquid stocks during each study period. The reason to investigate five markets and two study periods for each of

\footnotetext{
${ }^{5}$ Volume data are presented in Ozenbas (2002).

${ }^{6}$ LSE is a largely institutional market center compared to the other market centers in our sample that have both institutional and retail trading.

${ }^{7}$ Volume charts available upon request.
} 
them is to find the common features across these markets, and to establish that accentuated short-term volatility is a phenomenon shared by a wide array of equity market structures.

We are able to reach several conclusions from this study. First of all, our results show that the complexity of finding the price that best reflects the broad market is particularly magnified during the opening period. In all of the markets that we studied, opening volatility is accentuated, not only compared to the remaining intra-day periods of the trading day; it is also significantly accentuated compared to longer-term, daily or weekly volatility. Secondly, the pattern of intra-day volatility is a reverse J-shape with the highest spike at the beginning of the day with another, albeit less pronounced, spike towards the close. This finding is strikingly similar across markets despite the fact that the level of volatility varies considerably depending on the stocks included in the study. On the other hand, when we evaluate the level of closing volatility accentuation compared to longer differencing intervals, we find more mixed results. Despite the fact that volatility picks up as the market close approaches for all the markets, when we compare the level of volatility at the close with longer period volatilities we find that it is highly accentuated only for the London Stock Exchange, more mildly accentuated for Nasdaq and Euronext Paris, and not accentuated for either NYSE or Deutsche Boerse.

One area that would be a natural extension of this study is to find whether there are any variations in the volatility patterns of cross-listed stocks. The pattern of volume in the European markets suggests that the opening of trading in the US markets (and the consequent transfer of information) is important in the price formation process for

European stocks. Conversely, one would expect the American Depository Receipts to have a unique volatility/volume pattern, as opposed to the domestic stocks, due to the price discovery that carries over from their home market to the US market.

The intra-day pattern of stock price volatility (and volume) indicates a very intricate process of price discovery in equity markets. We are able to make statements about the quality and efficiency of markets through investigating these patterns. All told, an intra-day analysis of volatility (and volume) raises many exciting questions that should lead the way to new and fruitful research.

\section{REFERENCES}

1. Admati, R. Anat and Paul Pfleiderer, 1988, A theory of intraday patterns: Volume and price variability, The Review of Financial Studies 1, 3-40.

2. Amihud, Yakov and Haim Mendelson, 1987, Trading Mechanisms and Stock Returns: An Empirical Investigation, Journal of Finance 42, 533-553.

3. Bessembinder, H., 1994, Bid-Ask Spreads in the Inter-Bank Foreign Exchange Markets, Journal of Financial Economics 35, 317-348.

4. Brock, W and A. Kleidon, 1992, Periodic Market Closure and Trading Volume: A Model of Intraday Bids and Asks, Journal of Economic Dynamics and Control 16, 451-489.

5. Campbell, J., A. Lo, and C MacKinlay, 1997, The Econometrics of Financial Markets, Princeton University Press.

6. Gerety, M. and J.H. Mulheren, 1994, Price formation on stock exchanges: the evolution of trading within the day, Review of Financial Studies 7, 609-629.

7. Harris, Lawrence, 1986, A transaction data study of weekly and intradaily patterns in stock returns, Journal of Financial Economics 16, 99-118.

8. Hasbrouck, Joel and Robert A. Schwartz, 1988, Liquidity and execution costs in equity markets, Journal of Portfolio Management Spring, 10-15.

9. Jain, Prem and Gun-Ho Joh, 1988, The Dependence Between Hourly Prices and Trading Volume, Journal of Financial and Quantitative Analysis 23, 269-285.

10. Madhavan, A., M. Richardson, and M. Roomans, 1997, Why do security prices change? A transaction-level analysis of NYSE stocks, Review of Financial Studies 10, 1035-1064.

11. Ozenbas, Deniz, 2002, Intra-Day Price Volatility: A Reflection of Trading Friction, unpublished doctoral dissertation, Zicklin School of Business, Baruch College, CUNY.

12. Stoll, Hans, 2000, Friction, Journal of Finance 55, 1479-1515. 
13. Wood, Robert A., Thomas H. McInish, and Keith Ord, 1985, An investigation of transactions data for NYSE stocks, Journal of Finance 40, 723-741.

Table 1. Longer-Term Variance Ratio Tests And Percentage Of Stocks With Variance Ratios Greater Than Unity

On top, the average variance ratios are presented for each market and study period. Below each variance ratio is the percentages of stocks with variance ratios greater than unity for that market and study period. OC is the scaled open-to-close variance, OO is the scaled open-to-open variance, CC is the scaled close-to-close variance, OW is the scaled one-week variance, and TW is the scaled two-week variance. The first study period is January-June 2000 for New York Stock Exchange and Nasdaq Stock Market, JanuaryMay 2000 for Deutsche Boerse and London Stock Exchange, and January -March 2000 for Euronext Paris. The second study period is July-December 2000 for New York Stock Exchange and Nasdaq Stock Market, June-December 2000 for Deutsche Boerse and London Stock Exchange, and April-December 2000 for Euronext Paris.

\begin{tabular}{|c|c|c|c|c|}
\hline First Study Period & OC / TW & OO/TW & $\mathrm{CC} / \mathrm{TW}$ & OW / TW \\
\hline New York Stock Exchange & $\begin{array}{c}0.998 \\
54.17 \%\end{array}$ & $\begin{array}{c}1.183 \\
61.11 \%\end{array}$ & $\begin{array}{c}1.209 \\
69.44 \%\end{array}$ & $\begin{array}{c}1.035 \\
48.61 \%\end{array}$ \\
\hline Nasdaq Stock Market & $\begin{array}{c}1.073 \\
62.82 \% \\
\end{array}$ & $\begin{array}{c}1.23 \\
76.92 \% \\
\end{array}$ & $\begin{array}{c}1.221 \\
76.92 \% \\
\end{array}$ & $\begin{array}{c}1.028 \\
67.95 \% \\
\end{array}$ \\
\hline London Stock Exchange & $\begin{array}{c}\mathbf{1 . 3 0 6} \\
74.12 \%\end{array}$ & $\begin{array}{c}\mathbf{1 . 2 9 3} \\
50.59 \%\end{array}$ & $\begin{array}{c}1.212 \\
70.59 \%\end{array}$ & $\begin{array}{c}1.118 \\
67.06 \%\end{array}$ \\
\hline Euronext Paris & $\begin{array}{c}1.009 \\
56.41 \%\end{array}$ & $\begin{array}{c}\mathbf{1 . 3 3 6} \\
69.23 \%\end{array}$ & $\begin{array}{c}1.235 \\
61.54 \% \\
\end{array}$ & $\begin{array}{c}1.072 \\
58.97 \%\end{array}$ \\
\hline Deutsche Boerse & $\begin{array}{c}1.1 \\
60.71 \% \\
\end{array}$ & $\begin{array}{c}\mathbf{1 . 3 2} \\
89.29 \% \\
\end{array}$ & $\begin{array}{c}\mathbf{1 . 2 6 5} \\
75.00 \% \\
\end{array}$ & $\begin{array}{c}1.048 \\
57.14 \% \\
\end{array}$ \\
\hline Second Study Period & OC / TW & OO/TW & CC/TW & OW / TW \\
\hline New York Stock Exchange & $\begin{array}{c}\mathbf{0 . 7 2 9} \\
36.11 \%\end{array}$ & $\begin{array}{c}0.993 \\
61.11 \%\end{array}$ & $\begin{array}{c}0.992 \\
55.56 \%\end{array}$ & $\begin{array}{c}1.094 \\
56.94 \%\end{array}$ \\
\hline Nasdaq Stock Market & $\begin{array}{c}1.009 \\
56.41 \% \\
\end{array}$ & $\begin{array}{c}\mathbf{1 . 3 0 1} \\
80.77 \% \\
\end{array}$ & $\begin{array}{c}1.223 \\
67.95 \% \\
\end{array}$ & $\begin{array}{c}1.108 \\
60.26 \% \\
\end{array}$ \\
\hline London Stock Exchange & $\begin{array}{c}\mathbf{1 . 3 6 7} \\
80.00 \% \\
\end{array}$ & $\begin{array}{c}\mathbf{1 . 2 4 6} \\
52.27 \% \\
\end{array}$ & $\begin{array}{c}\mathbf{1 . 2 9} \\
76.14 \% \\
\end{array}$ & $\begin{array}{c}1.048 \\
55.29 \% \\
\end{array}$ \\
\hline Euronext Paris & $\begin{array}{c}1.201 \\
82.05 \% \\
\end{array}$ & $\begin{array}{c}\mathbf{1 . 5 9 1} \\
92.31 \% \\
\end{array}$ & $\begin{array}{c}\mathbf{1 . 2 7 9} \\
82.05 \% \\
\end{array}$ & $\begin{array}{c}1.098 \\
69.23 \% \\
\end{array}$ \\
\hline Deutsche Boerse & $\begin{array}{c}1.068 \\
67.86 \%\end{array}$ & $\begin{array}{c}1.199 \\
75.00 \%\end{array}$ & $\begin{array}{c}1.188 \\
67.86 \%\end{array}$ & $\begin{array}{c}1.016 \\
67.86 \%\end{array}$ \\
\hline
\end{tabular}

Bold entries indicate significantly different than unity at the 5\% confidence level. Bold and italic entries indicate significantly different than unity at the $1 \%$ confidence level. 
Table 2. Intra-Day Variance Ratio Tests, New York Stock Exchange

Intra-day variance ratios are presented for each half hour period during the trading day. INT is the scaled intra-day half hour variance, $\mathrm{OC}$ is the scaled open-to-close variance, $\mathrm{OO}$ is the scaled open-to-open variance, $\mathrm{CC}$ is the scaled close-to-close variance, OW is the scaled one-week variance, and TW is the scaled two-week variance. The percentages of stocks with variance ratios greater then unity are also presented below the market variance ratios. The study period is July-December 2000 for New York Stock Exchange.

\begin{tabular}{|c|c|c|c|c|c|}
\hline INT Ending & INT/OC & INT/OO & INT/CC & INT/OW & INT/TW \\
\hline \multirow[t]{2}{*}{ 10:00 } & 2.674 & 2.550 & 2.551 & 2.314 & 2.531 \\
\hline & $100 \%$ & $94 \%$ & $94 \%$ & $94 \%$ & $94 \%$ \\
\hline \multirow[t]{2}{*}{$10: 30$} & 1.839 & 1.350 & 1.351 & 1.225 & 1.340 \\
\hline & $92 \%$ & $63 \%$ & $63 \%$ & $54 \%$ & $63 \%$ \\
\hline \multirow[t]{2}{*}{ 11:00 } & 1.362 & 1.000 & 1.000 & 0.907 & 0.992 \\
\hline & $47 \%$ & $28 \%$ & $28 \%$ & $26 \%$ & $28 \%$ \\
\hline \multirow[t]{2}{*}{$11: 30$} & 0.962 & 0.706 & 0.706 & 0.641 & 0.701 \\
\hline & $32 \%$ & $13 \%$ & $13 \%$ & $8 \%$ & $13 \%$ \\
\hline \multirow[t]{2}{*}{$12: 00$} & 0.824 & 0.605 & 0.605 & 0.549 & 0.600 \\
\hline & $24 \%$ & $10 \%$ & $10 \%$ & $8 \%$ & $10 \%$ \\
\hline \multirow[t]{2}{*}{$12: 30$} & 0.655 & 0.481 & 0.481 & 0.437 & 0.477 \\
\hline & $10 \%$ & $6 \%$ & $6 \%$ & $6 \%$ & $6 \%$ \\
\hline \multirow[t]{2}{*}{$1: 00$} & 0.568 & 0.417 & 0.417 & 0.378 & 0.414 \\
\hline & $8 \%$ & $6 \%$ & $6 \%$ & $4 \%$ & $6 \%$ \\
\hline \multirow[t]{2}{*}{$1: 30$} & 0.555 & 0.407 & 0.408 & 0.370 & 0.404 \\
\hline & $8 \%$ & $4 \%$ & $4 \%$ & $4 \%$ & $4 \%$ \\
\hline \multirow[t]{2}{*}{$2: 00$} & 0.596 & 0.437 & 0.438 & 0.397 & 0.434 \\
\hline & $11 \%$ & $6 \%$ & $6 \%$ & $3 \%$ & $6 \%$ \\
\hline \multirow[t]{2}{*}{$2: 30$} & 0.639 & 0.469 & 0.469 & 0.426 & 0.466 \\
\hline & $13 \%$ & $10 \%$ & $10 \%$ & $10 \%$ & $10 \%$ \\
\hline \multirow[t]{2}{*}{$3: 00$} & 0.727 & 0.534 & 0.534 & 0.484 & 0.530 \\
\hline & $14 \%$ & $8 \%$ & $8 \%$ & $7 \%$ & $8 \%$ \\
\hline \multirow[t]{2}{*}{$3: 30$} & 0.818 & 0.601 & 0.601 & 0.545 & 0.596 \\
\hline & $21 \%$ & $8 \%$ & $8 \%$ & $8 \%$ & $8 \%$ \\
\hline \multirow[t]{2}{*}{ 4:00 } & 1.017 & 0.747 & 0.747 & 0.678 & 0.741 \\
\hline & $33 \%$ & $17 \%$ & $17 \%$ & $13 \%$ & $17 \%$ \\
\hline
\end{tabular}

Bold entries indicate significantly different than unity at the 5\% confidence level. Bold and italic entries indicate significantly different than unity at the $1 \%$ confidence level. 
Table3. Intra-Day Variance Ratio Tests, NASDAQ Stock Market

Intra-day variance ratios are presented for each half hour period during the trading day. INT is the scaled intra-day half hour variance, $\mathrm{OC}$ is the scaled open-to-close variance, $\mathrm{OO}$ is the scaled open-to-open variance, $\mathrm{CC}$ is the scaled close-to-close variance, $\mathrm{OW}$ is the scaled one-week variance, and TW is the scaled two-week variance. The percentages of stocks with variance ratios greater then unity are also presented below the market variance ratios. The study period is July-December 2000 for Nasdaq Stock Market.

\begin{tabular}{|c|c|c|c|c|c|}
\hline INT Ending & INT/OC & INT/OO & INT/CC & INT/OW & INT/TW \\
\hline \multirow[t]{2}{*}{$10: 00$} & 2.868 & 2.222 & 2.365 & 2.609 & 2.892 \\
\hline & $99 \%$ & $90 \%$ & $92 \%$ & $95 \%$ & $99 \%$ \\
\hline \multirow[t]{2}{*}{$10: 30$} & 1.590 & 1.232 & 1.311 & 1.447 & 1.604 \\
\hline & $73 \%$ & $55 \%$ & $60 \%$ & $68 \%$ & $73 \%$ \\
\hline \multirow[t]{2}{*}{$11: 00$} & 1.286 & 0.996 & 1.060 & 1.170 & 1.297 \\
\hline & $64 \%$ & $44 \%$ & $49 \%$ & $56 \%$ & $64 \%$ \\
\hline \multirow[t]{2}{*}{$11: 30$} & 0.830 & 0.643 & 0.684 & 0.755 & 0.837 \\
\hline & $26 \%$ & $13 \%$ & $18 \%$ & $21 \%$ & $26 \%$ \\
\hline \multirow[t]{2}{*}{$12: 00$} & 0.712 & 0.551 & 0.587 & 0.648 & 0.718 \\
\hline & $18 \%$ & $6 \%$ & $8 \%$ & $14 \%$ & $18 \%$ \\
\hline \multirow[t]{2}{*}{$12: 30$} & 0.584 & 0.453 & 0.482 & 0.531 & 0.589 \\
\hline & $10 \%$ & $4 \%$ & $4 \%$ & $5 \%$ & $10 \%$ \\
\hline \multirow[t]{2}{*}{ 1:00 } & 0.479 & 0.371 & 0.395 & 0.436 & 0.483 \\
\hline & $3 \%$ & $3 \%$ & $3 \%$ & $3 \%$ & $3 \%$ \\
\hline \multirow[t]{2}{*}{$1: 30$} & 0.523 & 0.405 & 0.431 & 0.476 & 0.528 \\
\hline & $4 \%$ & $1 \%$ & $1 \%$ & $3 \%$ & $5 \%$ \\
\hline \multirow[t]{2}{*}{$2: 00$} & 0.590 & 0.457 & 0.487 & 0.537 & 0.595 \\
\hline & $12 \%$ & $3 \%$ & $4 \%$ & $8 \%$ & $13 \%$ \\
\hline \multirow[t]{2}{*}{$2: 30$} & 0.671 & 0.520 & 0.554 & 0.611 & 0.677 \\
\hline & $15 \%$ & $4 \%$ & $5 \%$ & $10 \%$ & $15 \%$ \\
\hline \multirow[t]{2}{*}{$3: 00$} & 0.773 & 0.599 & 0.637 & 0.703 & 0.779 \\
\hline & $26 \%$ & $12 \%$ & $15 \%$ & $21 \%$ & $26 \%$ \\
\hline \multirow[t]{2}{*}{$3: 30$} & 0.932 & 0.722 & 0.769 & 0.848 & 0.940 \\
\hline & $38 \%$ & $21 \%$ & $23 \%$ & $33 \%$ & $40 \%$ \\
\hline \multirow[t]{2}{*}{$4: 00$} & 1.367 & 1.059 & 1.127 & 1.244 & 1.378 \\
\hline & $68 \%$ & $50 \%$ & $59 \%$ & $62 \%$ & $68 \%$ \\
\hline
\end{tabular}

Bold entries indicate significantly different than unity at the 5\% confidence level. Bold and italic entries indicate significantly different than unity at the $1 \%$ confidence level. 
Table 4. Intra-Day Variance Ratio Tests, London Stock Exchange

Intra-day variance ratios are presented for each half hour period during the trading day. INT is the scaled intra-day half hour variance, $\mathrm{OC}$ is the scaled open-to-close variance, $\mathrm{OO}$ is the scaled open-to-open variance, $\mathrm{CC}$ is the scaled close-to-close variance, $\mathrm{OW}$ is the scaled one-week variance, and TW is the scaled two-week variance. The percentages of stocks with variance ratios greater then unity are also presented below the market variance ratios. The study period is June-December 2000 for London Stock Exchange.

\begin{tabular}{|c|c|c|c|c|c|}
\hline INT Ending & INT/OC & INT/OO & INT/CC & INT/OW & INT/TW \\
\hline $8: 30$ & $\begin{array}{c}9.374 \\
98 \% \\
\end{array}$ & $\begin{array}{c}10.427 \\
99 \% \\
\end{array}$ & $\begin{array}{c}10.074 \\
99 \% \\
\end{array}$ & $\begin{array}{c}12.314 \\
99 \% \\
\end{array}$ & $\begin{array}{c}12.992 \\
99 \% \\
\end{array}$ \\
\hline $9: 00$ & $\begin{array}{c}2.196 \\
82 \%\end{array}$ & $\begin{array}{c}2.442 \\
86 \%\end{array}$ & $\begin{array}{c}2.360 \\
85 \%\end{array}$ & $\begin{array}{c}2.884 \\
90 \%\end{array}$ & $\begin{array}{c}\mathbf{3 . 0 4 3} \\
91 \%\end{array}$ \\
\hline $9: 30$ & $\begin{array}{c}1.531 \\
75 \% \\
\end{array}$ & $\begin{array}{c}1.703 \\
80 \% \\
\end{array}$ & $\begin{array}{c}1.645 \\
80 \% \\
\end{array}$ & $\begin{array}{c}2.011 \\
86 \% \\
\end{array}$ & $\begin{array}{c}2.121 \\
89 \% \\
\end{array}$ \\
\hline $10: 00$ & $\begin{array}{l}1.135 \\
52 \%\end{array}$ & $\begin{array}{c}\mathbf{1 . 2 6 2} \\
59 \%\end{array}$ & $\begin{array}{l}1.219 \\
56 \%\end{array}$ & $\begin{array}{c}1.491 \\
73 \%\end{array}$ & $\begin{array}{c}1.573 \\
77 \%\end{array}$ \\
\hline $10: 30$ & $\begin{array}{l}1.040 \\
40 \%\end{array}$ & $\begin{array}{l}1.157 \\
45 \%\end{array}$ & $\begin{array}{l}1.117 \\
43 \%\end{array}$ & $\begin{array}{c}\mathbf{1 . 3 6 6} \\
59 \%\end{array}$ & $\begin{array}{c}1.441 \\
64 \%\end{array}$ \\
\hline $11: 00$ & $\begin{array}{c}0.947 \\
31 \% \\
\end{array}$ & $\begin{array}{c}1.054 \\
41 \% \\
\end{array}$ & $\begin{array}{l}1.018 \\
36 \% \\
\end{array}$ & $\begin{array}{c}1.244 \\
58 \% \\
\end{array}$ & $\begin{array}{c}\mathbf{1 . 3 1 3} \\
61 \% \\
\end{array}$ \\
\hline $11: 30$ & $\begin{array}{c}\mathbf{0 . 7 5 4} \\
22 \% \\
\end{array}$ & $\begin{array}{c}0.839 \\
28 \% \\
\end{array}$ & $\begin{array}{c}0.810 \\
24 \% \\
\end{array}$ & $\begin{array}{c}0.990 \\
35 \% \\
\end{array}$ & $\begin{array}{c}1.045 \\
38 \% \\
\end{array}$ \\
\hline $12: 00$ & $\begin{array}{c}0.688 \\
22 \% \\
\end{array}$ & $\begin{array}{c}\mathbf{0 . 7 6 5} \\
24 \% \\
\end{array}$ & $\begin{array}{c}\mathbf{0 . 7 3 9} \\
23 \% \\
\end{array}$ & $\begin{array}{c}0.904 \\
35 \% \\
\end{array}$ & $\begin{array}{c}0.953 \\
39 \% \\
\end{array}$ \\
\hline $12: 30$ & $\begin{array}{c}0.644 \\
20 \% \\
\end{array}$ & $\begin{array}{c}0.717 \\
23 \% \\
\end{array}$ & $\begin{array}{c}\mathbf{0 . 6 9 2} \\
20 \% \\
\end{array}$ & $\begin{array}{c}0.846 \\
32 \% \\
\end{array}$ & $\begin{array}{c}0.893 \\
36 \% \\
\end{array}$ \\
\hline $1: 00$ & $\begin{array}{c}0.612 \\
11 \% \\
\end{array}$ & $\begin{array}{c}0.681 \\
17 \% \\
\end{array}$ & $\begin{array}{c}0.658 \\
14 \% \\
\end{array}$ & $\begin{array}{c}0.805 \\
23 \% \\
\end{array}$ & $\begin{array}{c}0.849 \\
27 \% \\
\end{array}$ \\
\hline $1: 30$ & $\begin{array}{c}0.572 \\
13 \% \\
\end{array}$ & $\begin{array}{c}\mathbf{0 . 6 3 6} \\
17 \% \\
\end{array}$ & $\begin{array}{c}0.614 \\
17 \% \\
\end{array}$ & $\begin{array}{c}\mathbf{0 . 7 5 1} \\
24 \% \\
\end{array}$ & $\begin{array}{c}0.792 \\
24 \% \\
\end{array}$ \\
\hline $2: 00$ & $\begin{array}{c}0.603 \\
13 \% \\
\end{array}$ & $\begin{array}{c}0.671 \\
16 \% \\
\end{array}$ & $\begin{array}{c}0.648 \\
13 \% \\
\end{array}$ & $\begin{array}{c}0.792 \\
24 \% \\
\end{array}$ & $\begin{array}{c}0.835 \\
25 \% \\
\end{array}$ \\
\hline $2: 30$ & $\begin{array}{c}\mathbf{0 . 6 2 9} \\
15 \% \\
\end{array}$ & $\begin{array}{c}0.700 \\
17 \% \\
\end{array}$ & $\begin{array}{c}0.676 \\
16 \% \\
\end{array}$ & $\begin{array}{c}0.827 \\
27 \% \\
\end{array}$ & $\begin{array}{c}0.872 \\
31 \% \\
\end{array}$ \\
\hline $3: 00$ & $\begin{array}{c}0.951 \\
34 \% \\
\end{array}$ & $\begin{array}{l}1.058 \\
36 \% \\
\end{array}$ & $\begin{array}{l}1.022 \\
36 \% \\
\end{array}$ & $\begin{array}{c}1.249 \\
45 \% \\
\end{array}$ & $\begin{array}{c}\mathbf{1 . 3 1 8} \\
50 \% \\
\end{array}$ \\
\hline $3: 30$ & $\begin{array}{c}0.884 \\
28 \% \\
\end{array}$ & $\begin{array}{c}0.983 \\
33 \% \\
\end{array}$ & $\begin{array}{c}0.950 \\
31 \% \\
\end{array}$ & $\begin{array}{c}1.161 \\
45 \% \\
\end{array}$ & $\begin{array}{l}1.225 \\
52 \% \\
\end{array}$ \\
\hline 4:00 & $\begin{array}{l}1.029 \\
36 \% \\
\end{array}$ & $\begin{array}{c}1.145 \\
47 \% \\
\end{array}$ & $\begin{array}{c}1.106 \\
45 \% \\
\end{array}$ & $\begin{array}{c}\mathbf{1 . 3 5 2} \\
61 \% \\
\end{array}$ & $\begin{array}{c}1.427 \\
65 \% \\
\end{array}$ \\
\hline $4: 30$ & $\begin{array}{c}2.052 \\
91 \% \\
\end{array}$ & $\begin{array}{c}2.283 \\
92 \% \\
\end{array}$ & $\begin{array}{c}2.205 \\
91 \% \\
\end{array}$ & $\begin{array}{c}2.696 \\
97 \% \\
\end{array}$ & $\begin{array}{c}2.844 \\
97 \% \\
\end{array}$ \\
\hline Closing Call & $\begin{array}{c}2.193 \\
89 \% \\
\end{array}$ & $\begin{array}{c}2.440 \\
91 \% \\
\end{array}$ & $\begin{array}{c}2.357 \\
91 \% \\
\end{array}$ & $\begin{array}{c}2.881 \\
98 \% \\
\end{array}$ & $\begin{array}{c}3.040 \\
98 \% \\
\end{array}$ \\
\hline
\end{tabular}

Bold entries indicate significantly different than unity at the 5\% confidence level. Bold and italic entries indicate significantly different than unity at the $1 \%$ confidence level. 
Table 5. Intra-Day Variance Ratio Tests, Euronext Paris

Intra-day variance ratios are presented for each half hour period during the trading day. INT is the scaled intra-day half hour variance, $\mathrm{OC}$ is the scaled open-to-close variance, $\mathrm{OO}$ is the scaled open-to-open variance, $\mathrm{CC}$ is the scaled close-to-close variance, OW is the scaled one-week variance, and TW is the scaled two-week variance. The percentages of stocks with variance ratios greater then unity are also presented below the market variance ratios. The study period is April-December 2000 for Euronext Paris.

\begin{tabular}{|c|c|c|c|c|c|}
\hline INT Ending & INT/OC & INT/OO & INT/CC & INT/OW & INT/TW \\
\hline \multirow[t]{2}{*}{$9: 30$} & 2.855 & 2.155 & 2.681 & 3.122 & 3.429 \\
\hline & $97 \%$ & $97 \%$ & $97 \%$ & $100 \%$ & $100 \%$ \\
\hline \multirow[t]{2}{*}{$10: 00$} & 1.559 & 1.176 & 1.463 & 1.704 & 1.872 \\
\hline & $77 \%$ & $56 \%$ & $72 \%$ & $90 \%$ & $90 \%$ \\
\hline \multirow[t]{2}{*}{$10: 30$} & 1.176 & 0.888 & 1.104 & 1.286 & 1.412 \\
\hline & $62 \%$ & $36 \%$ & $59 \%$ & $64 \%$ & $69 \%$ \\
\hline \multirow[t]{2}{*}{$11: 00$} & 1.046 & 0.790 & 0.982 & 1.144 & 1.256 \\
\hline & $51 \%$ & $38 \%$ & $49 \%$ & $56 \%$ & $64 \%$ \\
\hline \multirow[t]{2}{*}{$11: 30$} & 0.889 & 0.671 & 0.835 & 0.972 & 1.067 \\
\hline & $41 \%$ & $23 \%$ & $33 \%$ & $56 \%$ & $64 \%$ \\
\hline \multirow[t]{2}{*}{$12: 00$} & 0.861 & 0.650 & 0.809 & 0.942 & 1.034 \\
\hline & $41 \%$ & $21 \%$ & $33 \%$ & $44 \%$ & $54 \%$ \\
\hline \multirow[t]{2}{*}{$12: 30$} & 0.745 & 0.562 & 0.700 & 0.815 & 0.895 \\
\hline & $33 \%$ & $10 \%$ & $28 \%$ & $33 \%$ & $38 \%$ \\
\hline \multirow[t]{2}{*}{$1: 00$} & 0.702 & 0.530 & 0.659 & 0.767 & 0.843 \\
\hline & $28 \%$ & $8 \%$ & $28 \%$ & $31 \%$ & $36 \%$ \\
\hline \multirow[t]{2}{*}{$1: 30$} & 0.627 & 0.473 & 0.588 & 0.685 & 0.752 \\
\hline & $18 \%$ & $10 \%$ & $15 \%$ & $23 \%$ & $28 \%$ \\
\hline \multirow[t]{2}{*}{$2: 00$} & 0.644 & 0.486 & 0.605 & 0.704 & 0.774 \\
\hline & $21 \%$ & $10 \%$ & $15 \%$ & $26 \%$ & $31 \%$ \\
\hline \multirow[t]{2}{*}{$2: 30$} & 0.637 & 0.481 & 0.598 & 0.697 & 0.765 \\
\hline & $21 \%$ & $3 \%$ & $18 \%$ & $23 \%$ & $26 \%$ \\
\hline \multirow[t]{2}{*}{$3: 00$} & 0.973 & 0.734 & 0.913 & 1.064 & 1.168 \\
\hline & $36 \%$ & $31 \%$ & $33 \%$ & $41 \%$ & $46 \%$ \\
\hline \multirow[t]{2}{*}{$3: 30$} & 0.780 & 0.589 & 0.732 & 0.853 & 0.937 \\
\hline & $31 \%$ & $10 \%$ & $21 \%$ & $33 \%$ & $36 \%$ \\
\hline \multirow[t]{2}{*}{ 4:00 } & 1.114 & 0.841 & 1.046 & 1.218 & 1.338 \\
\hline & $54 \%$ & $31 \%$ & $49 \%$ & $62 \%$ & $64 \%$ \\
\hline \multirow[t]{2}{*}{$4: 30$} & 1.143 & 0.862 & 1.073 & 1.250 & 1.372 \\
\hline & $54 \%$ & $33 \%$ & $49 \%$ & $62 \%$ & $67 \%$ \\
\hline \multirow[t]{2}{*}{$5: 00$} & 1.173 & 0.885 & 1.101 & 1.282 & 1.408 \\
\hline & $54 \%$ & $36 \%$ & $49 \%$ & $56 \%$ & $77 \%$ \\
\hline \multirow[t]{2}{*}{$5: 30$} & 1.552 & 1.171 & 1.457 & 1.697 & 1.863 \\
\hline & $79 \%$ & $64 \%$ & $77 \%$ & $85 \%$ & $87 \%$ \\
\hline \multirow[t]{2}{*}{ Closing Call } & 0.924 & 0.697 & 0.867 & 1.010 & 1.109 \\
\hline & $41 \%$ & $15 \%$ & $31 \%$ & $51 \%$ & $56 \%$ \\
\hline
\end{tabular}

Bold entries indicate significantly different than unity at the 5\% confidence level. Bold and italic entries indicate significantly different than unity at the $1 \%$ confidence level. 
Table 6. Intra-Day Variance Ratio Tests, Deutsche Boerse

Intra-day variance ratios are presented for each half hour period during the trading day. INT is the scaled intra-day half hour variance, OC is the scaled open-to-close variance, $\mathrm{OO}$ is the scaled open-to-open variance, $\mathrm{CC}$ is the scaled close-to-close variance, $\mathrm{OW}$ is the scaled one-week variance, and TW is the scaled two-week variance. The percentages of stocks with variance ratios greater then unity are also presented below the market variance ratios. The study period is June-December 2000 for Deutsche Boerse.

\begin{tabular}{|c|c|c|c|c|c|}
\hline INT Ending & INT/OC & INT/OO & INT/CC & INT/OW & INT/TW \\
\hline \multirow[t]{2}{*}{$9: 30$} & 3.516 & 2.991 & 3.019 & 3.457 & 3.118 \\
\hline & $100 \%$ & $100 \%$ & $100 \%$ & $100 \%$ & $100 \%$ \\
\hline \multirow[t]{2}{*}{$10: 00$} & 1.609 & 1.369 & 1.382 & 1.582 & 1.427 \\
\hline & $100 \%$ & $96 \%$ & $96 \%$ & $100 \%$ & $100 \%$ \\
\hline \multirow[t]{2}{*}{$10: 30$} & 1.252 & 1.065 & 1.075 & 1.231 & 1.110 \\
\hline & $89 \%$ & $79 \%$ & $79 \%$ & $89 \%$ & $82 \%$ \\
\hline \multirow[t]{2}{*}{ 11:00 } & 1.020 & 0.867 & 0.876 & 1.003 & 0.904 \\
\hline & $79 \%$ & $61 \%$ & $61 \%$ & $79 \%$ & $71 \%$ \\
\hline \multirow[t]{2}{*}{$11: 30$} & 0.898 & 0.764 & 0.771 & 0.883 & 0.797 \\
\hline & $61 \%$ & $43 \%$ & $43 \%$ & $57 \%$ & $43 \%$ \\
\hline \multirow[t]{2}{*}{$12: 00$} & 0.828 & 0.704 & 0.711 & 0.814 & 0.734 \\
\hline & $46 \%$ & $39 \%$ & $39 \%$ & $46 \%$ & $43 \%$ \\
\hline \multirow[t]{2}{*}{$12: 30$} & 0.811 & 0.690 & 0.696 & 0.797 & 0.719 \\
\hline & $57 \%$ & $32 \%$ & $43 \%$ & $54 \%$ & $43 \%$ \\
\hline \multirow[t]{2}{*}{$1: 00$} & 0.687 & 0.585 & 0.590 & 0.676 & 0.610 \\
\hline & $36 \%$ & $18 \%$ & $18 \%$ & $32 \%$ & $25 \%$ \\
\hline \multirow[t]{2}{*}{$1: 30$} & 0.723 & 0.615 & 0.621 & 0.711 & 0.641 \\
\hline & $32 \%$ & $18 \%$ & $18 \%$ & $29 \%$ & $18 \%$ \\
\hline \multirow[t]{2}{*}{$2: 00$} & 0.720 & 0.612 & 0.618 & 0.708 & 0.639 \\
\hline & $43 \%$ & $25 \%$ & $25 \%$ & $39 \%$ & $25 \%$ \\
\hline \multirow[t]{2}{*}{$2: 30$} & 0.681 & 0.579 & 0.584 & 0.669 & 0.604 \\
\hline & $29 \%$ & $21 \%$ & $21 \%$ & $29 \%$ & $25 \%$ \\
\hline \multirow[t]{2}{*}{$3: 00$} & 0.789 & 0.671 & 0.677 & 0.776 & 0.699 \\
\hline & $46 \%$ & $29 \%$ & $29 \%$ & $46 \%$ & $39 \%$ \\
\hline \multirow[t]{2}{*}{$3: 30$} & 0.694 & 0.590 & 0.596 & 0.683 & 0.616 \\
\hline & $36 \%$ & $25 \%$ & $25 \%$ & $36 \%$ & $25 \%$ \\
\hline \multirow[t]{2}{*}{ 4:00 } & 1.042 & 0.886 & 0.894 & 1.024 & 0.924 \\
\hline & $68 \%$ & $46 \%$ & $46 \%$ & $68 \%$ & $54 \%$ \\
\hline \multirow[t]{2}{*}{$4: 30$} & 1.049 & 0.892 & 0.900 & 1.031 & 0.930 \\
\hline & $68 \%$ & $54 \%$ & $57 \%$ & $68 \%$ & $64 \%$ \\
\hline \multirow[t]{2}{*}{ 5:00 } & 1.120 & 0.952 & 0.962 & 1.101 & 0.993 \\
\hline & $71 \%$ & $64 \%$ & $68 \%$ & $71 \%$ & $68 \%$ \\
\hline \multirow[t]{2}{*}{$5: 30$} & 1.198 & 1.019 & 1.029 & 1.178 & 1.063 \\
\hline & $82 \%$ & $79 \%$ & $79 \%$ & $82 \%$ & $79 \%$ \\
\hline \multirow[t]{2}{*}{ 6:00 } & 0.780 & 0.663 & 0.670 & 0.767 & 0.692 \\
\hline & $54 \%$ & $43 \%$ & $43 \%$ & $54 \%$ & $43 \%$ \\
\hline \multirow[t]{2}{*}{$6: 30$} & 0.481 & 0.409 & 0.413 & 0.473 & 0.427 \\
\hline & $7 \%$ & $4 \%$ & $4 \%$ & $7 \%$ & $7 \%$ \\
\hline \multirow[t]{2}{*}{ 7:00 } & 0.360 & 0.306 & 0.309 & 0.354 & 0.319 \\
\hline & $0 \%$ & $0 \%$ & $0 \%$ & $0 \%$ & $0 \%$ \\
\hline \multirow[t]{2}{*}{$7: 30$} & 0.375 & 0.319 & 0.322 & 0.368 & 0.332 \\
\hline & $7 \%$ & $0 \%$ & $0 \%$ & $7 \%$ & $0 \%$ \\
\hline \multirow[t]{2}{*}{$8: 00$} & 0.535 & 0.455 & 0.460 & 0.526 & 0.475 \\
\hline & $14 \%$ & $4 \%$ & $4 \%$ & $14 \%$ & $7 \%$ \\
\hline \multirow[t]{2}{*}{ Closing Call } & 1.131 & 0.962 & 0.971 & 1.112 & 1.003 \\
\hline & $61 \%$ & $54 \%$ & $54 \%$ & $61 \%$ & $54 \%$ \\
\hline
\end{tabular}

Bold entries indicate significantly different than unity at the 5\% confidence level. Bold and italic entries indicate significantly different than unity at the $1 \%$ confidence level. 